\title{
Structural Behavior of Reinforced Self-Compacted Engineered Cementitious Composite Beams
}

\author{
Bashar S. Mohammed, ${ }^{1}$ M. F. Nuruddin, ${ }^{1}$ Muhammad Aswin, ${ }^{1}$ \\ Nursyuhada Mahamood, ${ }^{1}$ and Hashem Al-Mattarneh ${ }^{2}$ \\ ${ }^{1}$ Department of Civil and Environmental Engineering, Universiti Teknologi PETRONAS, 32610 Bandar Seri Iskandar, \\ Perak Darul Ridzuan, Malaysia \\ ${ }^{2}$ Civil Engineering Department, Najran University, Najran 11001, Saudi Arabia
}

Correspondence should be addressed to Bashar S. Mohammed; bashar.mohammed@petronas.com.my

Received 1 July 2016; Revised 6 September 2016; Accepted 29 September 2016

Academic Editor: Jae-Han Lim

Copyright (C) 2016 Bashar S. Mohammed et al. This is an open access article distributed under the Creative Commons Attribution License, which permits unrestricted use, distribution, and reproduction in any medium, provided the original work is properly cited.

Eight large-scale reinforced self-compacted engineered cementitious composite (R-SC-ECC) beams with different steel reinforcement ratios have been designed, prepared, cast, cured, and tested to failure at the age of 28 days. The experimental results have been compared with theoretical values predicted using EC2, RILEM, and VecTor2 models. Results show that failure modes in flexure and shear of R-SC-ECC beams are comparable to that of normal reinforced concrete beam. Nevertheless, contrary to VecTor2, models of EC2 and RILEM are not suitable for predicting reasonable ultimate moments for the beams, while results using VecTor2 model have successfully predicted the failure modes and load-deflection curves for all R-SC-ECC beams. It has been concluded that R-SC-ECC fall in the category of ductility class medium to high which gives advantages of using R-SC-ECC beams in regions susceptible to seismic activities.

\section{Introduction}

The structural applications for plain concrete are limited due to its low tensile strength, low strain capacity, and brittle behavior. Therefore, steel bars have been introduced to resist the tensile stress and achieve ductile behavior of reinforced concrete (RC) element, and, consequently, RC has become a dominant construction material. However, in some structural applications, such as link slab for jointless bridge deck, connection joints, slabs under indentation load, and RC elements subjected to seismic loading, high steel reinforcement ratio is required $[1,2]$. This led to unnecessary stiffening of the RC elements and also causes difficulties in proper compaction of fresh concrete around steel bars during concreting which in turn adversely affects the RC composite action. Therefore, fibers have been added to concrete to increase tensile strength and strain capacity and also improve ductility, which subsequently reduces the steel reinforcement ratio in RC elements. To attain tensile elastic-strain hardening behavior accompanied by multiple cracks, high performance fiber reinforced cementitious composites (HPFRCCs) containing $4 \%$ to $20 \%$ fibers have been developed [3]. However, researchers reported problems of HPFRCCs such as poor workability, less homogeneity, and fibers balling occurrence $[1,2]$. Engineered cementitious composite (ECC) is a special class of HPFRCCs [4]. Unlike HPFRCCs, ECC requires much lower fibers, not greater than $2 \%$ volume fraction of polymeric fibers for comparable mechanical properties. ECC has high tensile strength from 4 to $6 \mathrm{MPa}$ [4] and large strain capacity between 3\% and 5\% [5] and also exhibits high ductility by optimizing the microstructure of the composite [6]. In addition, ECC has the ability to confine crack width up to an average of less than 60 microns up to failure [7]. Further details on ECC properties and behavior have been reported by other researchers [8-11]. On the other hand, self-compacted concrete (SCC) is nonsegregating, nonbleeding, and highly cohesive concrete [12]. It has super fluidity that enables it to fill the formworks by its gravity completely, achieving adequate consolidation and encapsulating reinforcement 
TABLE 1: Mix proportions of SC-ECC.

\begin{tabular}{lc}
\hline Ingredients & Amount \\
\hline Cement $(\mathrm{OPC}), \mathrm{kg} / \mathrm{m}^{3}$ & 583 \\
Fly Ash, $\mathrm{kg} / \mathrm{m}^{3}$ & 700 \\
Fine aggregate, $\mathrm{kg} / \mathrm{m}^{3}$ & 467 \\
Water-cement ratio & 0.32 \\
Polyvinyl alcohol, \% & 2 \\
Super plasticizer, $\mathrm{kg} / \mathrm{m}^{3}$ & 9.5 \\
\hline
\end{tabular}

without external mechanical compaction [13]. Other advantages have been also reported on using SCC; for example, it requires a smaller number of workers in pouring concrete and it has reduced noise level associated with vibrating of normal concrete, better durability, time-saving property, and better quality [12-14]. Therefore, the main objective of the work presented in this paper is to investigate the structural behavior of large-scale reinforced self-compacted engineered cementitious composite (R-SC-ECC) beams. Theoretical models such as Eurocode2 model for high strength concrete, RILEM model for fiber reinforced concrete, and finite element VecTor2 model have been investigated as well. Theoretical values have been compared with the experimental results to evaluate their suitability and accuracy in predicting the structural performance of R-SC-ECC beams.

\section{Experimental Works}

Eight large-scale R-SC-ECC beams were prepared, cast, cured, and tested up to failure at the age of 28 days. All beams have a rectangular cross section of $150 \mathrm{~mm}$ breadth and $300 \mathrm{~mm}$ height, with a total span length of $2600 \mathrm{~mm}$ and effective span (center to center of supports) of $2300 \mathrm{~mm}$.

2.1. Mix Proportions. To improve quality of hardened ECC and also create a better working environment, self-compacting ECC (SC-ECC) has been developed. The necessity of using SC-ECC is to ensure the flow ability of the ECC under its own weight in narrow steel-congested sections. This is important to avoid bleeding and segregation of fresh ECC and also to ensure optimum bonding with steel bars and honeycomb free of hardened ECC. As shown in Table 1, a mix proportion of SC-ECC has been selected and prepared in accordance with the requirements of ACI committee 211.2-98, while the mixing procedure is described by Mohammed et al. [6]. To assess the fresh properties of the SC-ECC, four tests have been conducted: slump flow, $T_{50 \mathrm{~cm}}$ slump flow, Vfunnel, and L-box. Test results are shown in Table 2; the ECC mixture has fresh properties satisfying the self-compacting requirements as shown in Table 3. Samples of the SC-ECC have been prepared, cast, cured, and tested at the age of 28 days to determine the hardened properties as shown in Table 4. Experimental setup for the flexural, compression stress-strain, and direct tensile tests can be seen in Figures 1,2 , and 3 . In addition, the air dry density has been found to be $2204 \mathrm{~kg} / \mathrm{m}^{3}$.

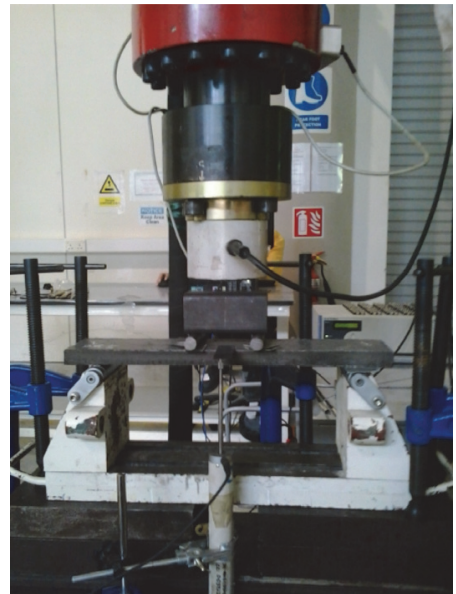

FIGURE 1: Flexural test for ECC.

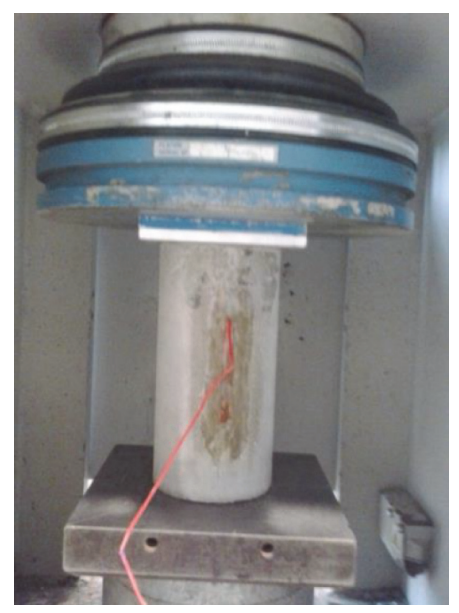

FIgURE 2: Compression stress-strain test for ECC.

2.2. Test Specimens. In reinforced concrete (RC) design, concrete tensile strength is assumed as zero; therefore, all tensile forces (below neutral axis of the section) are to be resisted by steel reinforcement in tension. This assumption is true for normal concrete which usually has very low tensile strength. However, fiber reinforced concrete has a more significant value of tensile strength. ECC is a special type of fiber reinforced concrete and exhibits property of steel-like behavior. With the increase of using reinforced ECC components in construction industry, it is important to evaluate the suitability of fiber reinforced concrete (FRC) design models to be used in the design of reinforced ECC members. To achieve this objective, eight large-scale reinforced SC-ECC beams have been designed, prepared, cast, cured, and tested up to failure at the age of 28 days. In view of a single variable as steel reinforcement ratio, all beams have the same cross-sectional area with dimensions of $150 \mathrm{~mm}$ width and $300 \mathrm{~mm}$ overall height. In this study, the required longitudinal steel reinforcement was determined according to the requirements of EC2 (Section 9.2.1.1). The area of longitudinal steel reinforcement provided in each beam is greater than $112.4 \mathrm{~mm}^{2}$ and is not 
TABle 2: Fresh SC-ECC testing.

\begin{tabular}{lccccc}
\hline \multicolumn{1}{c}{ Slump flow } & \multicolumn{3}{c}{ L-box } \\
Slump flow diameter $(\mathrm{mm})$ & $T_{50}(\mathrm{sec})$ & $\begin{array}{c}\text { V-funnel } \\
t_{v}(\mathrm{sec})\end{array}$ & $h_{1}(\mathrm{~mm})$ & $h_{2}(\mathrm{~mm})$ & $h_{2} / h_{1}$ \\
\hline 788.5 & 3 & 7 & 102 & 94 & 0.92 \\
\hline
\end{tabular}

TABLE 3: Test methods for evaluating the fresh properties of selfcompacted concrete.

\begin{tabular}{lccc}
\hline \multirow{2}{*}{ Test method } & \multirow{2}{*}{ Test purpose } & \multicolumn{2}{c}{ Typical range } \\
& & Minimum & Maximum \\
\hline Slump flow & Viscosity/flow ability & $650 \mathrm{~mm}$ & $800 \mathrm{~mm}$ \\
$T_{50}$ slump flow & Viscosity/flow ability & $2 \mathrm{sec}$ & $5 \mathrm{sec}$ \\
V-funnel & Filling ability & $6 \mathrm{sec}$ & $12 \mathrm{sec}$ \\
L-box $\left(h_{2} / h_{1}\right)$ & Passing ability & 0.8 & 1.0 \\
\hline
\end{tabular}

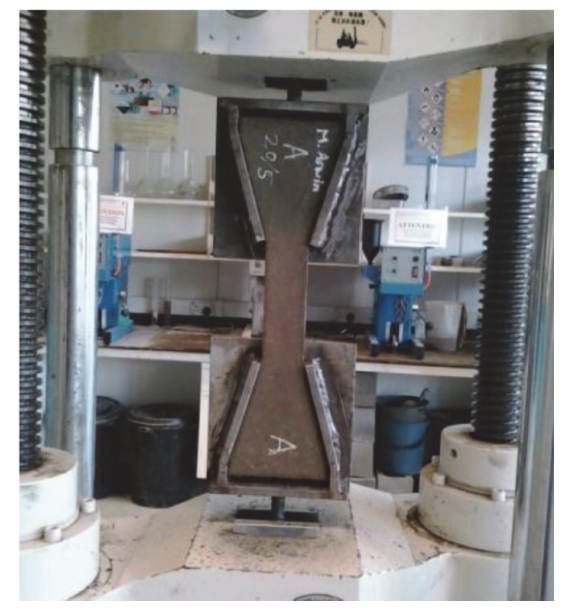

FIgure 3: Direct tensile test for ECC.

less than $54.6 \mathrm{~mm}^{2}$, which is the minimum area of steel reinforcement and is less than the maximum area of steel reinforcement, $1800 \mathrm{~mm}^{2}$. Variations of steel reinforcement ratio $(\rho)$ were taken based on the amount of longitudinal steel reinforcement utilized. The steel reinforcement details of beams are shown in Table 5. To support the aim of this study, fiber-full fraction ECC section along the beam has been utilized, while steel reinforcement ratio $(\rho)$ was varied. This is to obtain the effect of various steel reinforcement ratios against ultimate moment capacity, load-deformation relationship, and ductility ratio. The ultimate moment capacity of R-SCECC beams was investigated using different design models to achieve an appropriate design model in the designing of reinforced ECC beams.

The shear span $\left(a_{p}\right)$ and concrete cover are kept constant as $766 \mathrm{~mm}$ and $20 \mathrm{~mm}$, respectively. Shear design has been carried out in accordance with the requirement of EC2 and shear links are placed along the beam. Closed $8 \mathrm{~mm}$ diameter link has been used with spacing of $60 \mathrm{~mm}$ center/center to accommodate the shear requirement.

For each beam, two strain gages have been placed on the main tension bars to measure the tensile strains, while the concrete strain gages have been placed at one side of the beams' surfaces to measure the flexural strains development of SC-ECC during the test. The schematic diagram of the experimental setup is shown in Figure 4. The R-SC-ECC beams have been tested as simply supported using fourpoint flexural arrangement and constant loading rate of $0.1 \mathrm{kN} / \mathrm{sec}$ up to failure. Linear Variable Differential Transducers (LVDTs) have been positioned at the soffit of the beams to measure deflections.

\section{Results and Discussion}

3.1. Ultimate Moment Capacity. Moment capacity of the beam is the ultimate design moment that brings the beam to the maximum point. Various design codes adopt different safety factors in calculating the moment capacity. However, for normal reinforced concrete, tensile strength of concrete below neutral axis of the equivalent-rectangular stress block is assumed as zero. Therefore, the tensile concrete is negligible and only steel reinforcement in tension is supposed to resist the applied tensile forces, while, for reinforced-fiber reinforced concrete (R-FRC), both reinforcement and FRC are supposed to resist the applied tensile forces as shown in Figure 5. The moment capacity of FRC with ordinary reinforcing bars according to RILEM stress-strain relationship can be computed using

$$
M_{n}=A_{s} f_{y}\left(d-\frac{a}{2}\right)+f_{f t}(h-x) b z,
$$

where $A_{s}$ is the area of tension steel reinforcement, $f_{y}$ is the yield strength of steel reinforcement, $d$ is the effective depth of the section, $x$ is the depth of the neutral axis, $a=\beta_{1} x, \beta_{1}$ is the coefficient of compressive stress block, $f_{f t}$ is tensile strength of FRC, $h$ is the overall height of the section, $z$ is the internal lever arm and is equal to $0.5(h-x)+x\left(1-\beta_{1} / 2\right)$, and $b$ is the width of the section.

The EC2 [16] model is shown in Figure 6. Using ECC with compressive strength of $86.5 \mathrm{MPa}, 0.463 f_{c k} b s=0.87 f_{y k} A_{s}$, where $s=0.71 x$; therefore, the ultimate moment capacity is computed using

$$
M=F_{s t} \times z .
$$

Under reinforcement beam, the steel reinforcement is yielded if $x \leq x_{b}$, where $x$ is the depth of neutral axis and $x_{b}$ is the depth of neutral axis for balance condition. To determine $x_{b}$ for the R-ECC section (Figure 7), ultimate strain of ECC, $\varepsilon_{c u 2}=0.0026$ (from Table 3.1 of the EC2), and yield strain, $\varepsilon_{y}$, for steel bars diameters 10,12 , and $16 \mathrm{~mm}$ are 0.00235 , 0.00222 , and 0.00243 , respectively.

Finite element modelling package of VecTor2 [17] has also been used in the analysis of R-ECC beams in this study. 
TABle 4: Properties of hardened ECC.

\begin{tabular}{|c|c|c|c|c|}
\hline SC-ECC hardened property & Testing method & Number of samples and size & Unit & Average of the three samples \\
\hline Compressive strength & ASTM C39/C39M-04 A & 3 cylinders of $100 \mathrm{~mm}$ dia. and $200 \mathrm{~mm}$ height & $\mathrm{MPa}$ & 86.5 \\
\hline Splitting tensile strength & ASTM C496/C496M $\mp 04$ & 3 cylinders of $100 \mathrm{~mm}$ dia. and $200 \mathrm{~mm}$ height & $\mathrm{MPa}$ & 6.18 \\
\hline Flexural strength & ASTM C293-02 & 3 beams of $100 \times 24 \times 500 \mathrm{~mm}$ & $\mathrm{MPa}$ & 10.42 \\
\hline Elastic modulus & ASTM C469干02 & 3 cylinders of $100 \mathrm{~mm}$ dia. and $200 \mathrm{~mm}$ height & $\mathrm{GPa}$ & 22 \\
\hline Direct tensile strength & ASTM C 39; ASTM E 4 & 3 samples with the prism dog bone shape & $\mathrm{MPa}$ & 4.87 \\
\hline
\end{tabular}

TABLE 5: Steel reinforcement details of R-SC-ECC beams.

\begin{tabular}{lcccc}
\hline Beam number & Steel bar reinforcement & Yield stress $(\mathrm{MPa})$ & Section area $\left(\mathrm{mm}^{2}\right)$ & $\rho=100 A_{s} / b d(\%)$ \\
\hline B1 & $2 \varphi 12$ & 443 & 226.19 & 0.558 \\
B2 & $2 \varphi 10$ & 470 & 157.08 & 0.388 \\
B3 & $2 \varphi 16$ & 486 & 402.12 & 0.993 \\
B4 & $2 \varphi 12+1 \varphi 10$ & $443 ; 470$ & 304.7 & 0.752 \\
B5 & $2 \varphi 16+1 \varphi 12$ & $486 ; 443$ & 515.2 & 1.272 \\
B6 & $3 \varphi 16$ & 486 & 603.2 & 1.49 \\
B7 & $4 \varphi 16$ & 486 & 804.2 & 1.986 \\
B8 & $4 \varphi 16+1 \varphi 12$ & $486 ; 443$ & 917.29 & 2.03 \\
\hline
\end{tabular}

VecTor2 is a nonlinear finite element package to analyse two-dimensional reinforced concrete members. It has been theoretically developed and experimentally verified to predict load-deformation response for reinforced concrete elements which exhibit good crack distribution when subjected to short-term static monotonic, cyclic, and reverse cyclic loading.

The theoretical bases of VecTor2 are the Modified Compression Field Theory (MCFT) [18] and the Disturbed Stress Field Model (DSFM) [19], in which analytical models are subjected to normal and shear stresses for predicting the response of reinforced concrete elements. VecTor2 deals with cracked concrete as an orthotropic material with smearing and rotating cracks. MCFT assumes that the rotations of principle stress and strain fields are equal $\left(\theta=\theta_{\sigma}=\theta_{\varepsilon}\right)$, so that the prediction of shear stiffness and strength is always overestimated. DSFM can address the systematic deficiencies of MCFT, where the rotation of principal stress field tends to lag compared with the greater rotation of principal strain field $\left(\theta_{\sigma}<\theta_{\varepsilon}\right)$. Therefore, VecTor2 is an appropriate package for analysing reinforced ECC as it contains concrete, reinforcement, and bond models which can be selected based on trial and error to obtain the most appropriate model. A total of 628 elements have been used in the developing of R-ECC beams model. Three types of elements have been utilized, which are 264 rectangular elements, 216 triangular elements, and 148 truss elements, with total nodes of 439 .

As shown in Table 6 and Figure 8, the ratios of ultimate moment using VecTor2 model to experimental results are closer to 1 compared to RILEM and EC2 models. This is due to the ability of VecTor2 model to accommodate the actual properties of ECC which contributes to the accurate prediction of R-ECC beams behavior. RILEM model conservatively predicts the ultimate moments of R-ECC beams for small steel reinforcement ratio up to 0.752 , while for higher ratios the model underestimates the moments. This is due to the increase in the steel reinforcement ratio which leads to the increase of $x$ as well, which leads to a decrease in the ECC tensile force $\left(F_{f c, t}\right)$ as shown in

$$
F_{f c, t}=f_{f t}(h-x) b .
$$

However, EC2 model has failed to predict reasonable moment capacity due to negligence of tensile strength of the ECC as the model assumes that tensile strength of ECC is equal to zero.

3.2. Failure Modes and Crack Pattern. Two failure modes have been observed from testing R-SC-ECC beams, which are flexural failure for beams B1 to B6 as shown in Figure 9 and shear failure mode for beams B7 and B8 as shown in Figure 10. In general, the flexural failure of R-SC-ECC beams is comparable to that of normal reinforced concrete beams. Vertical hair cracks first appeared at the constant-moment zone. Due to the test loading increase, hair cracks extended upward and became more inclined toward the center of the beams combined with increasing cracks thickness until main steel bars yielded. The yielding of the steel bars is marked by the beams failure; however, beams continued to resist the applied load until the crushing of ECC occurred in the compression zone [20]. Yielding strain of longitudinal steel reinforcement has been surpassed in beams B1 to B6 as shown in Figure 11. The general requirement of EC2 is that RC crack width, $W_{\max }$, shall be limited so that it does not adversely affect the durability or functioning or appearance of the structure. Therefore, from Table $7.2 \mathrm{~N}$ of EC2, the maximum theoretical crack width for beams B1, B2, and B4 is $0.3 \mathrm{~mm}$ and for beams B3, B5, and B6 is $0.4 \mathrm{~mm}$. For cracking control, the minimum area of longitudinal steel reinforcement provided in each beam has been satisfied in accordance with the requirements of EC2 (Section 9.2.1.1). However, as shown in Table 7, flexural crack widths of RSC-ECC beams at service loads have exceeded the limit. 


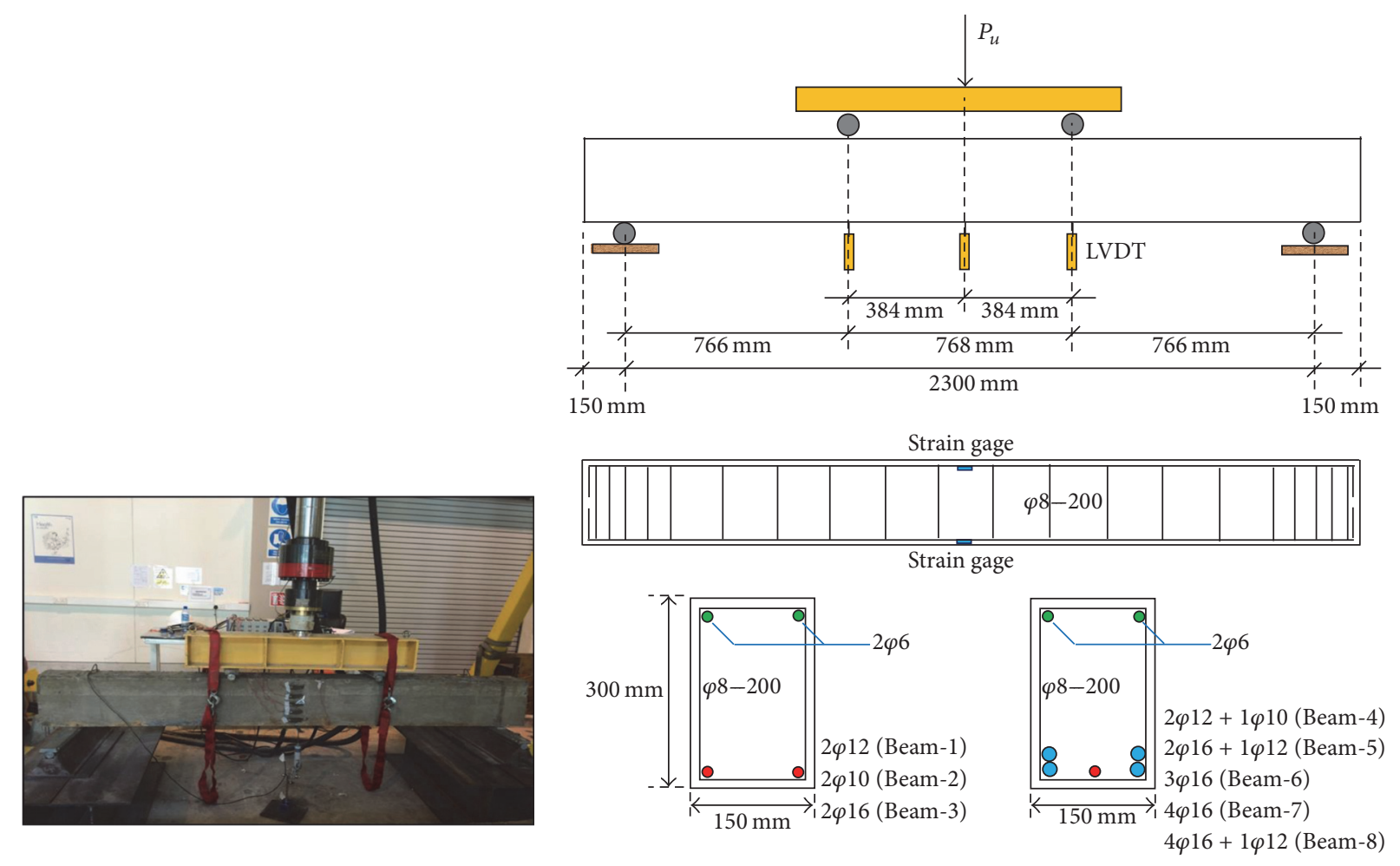

(a)

(b)

FIGURE 4: Test setup and details for R-SC-ECC beams.

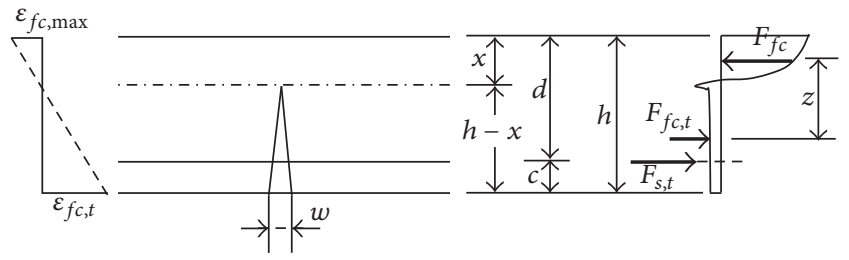

FIGURE 5: Stress-strain relationship, RILEM [15].

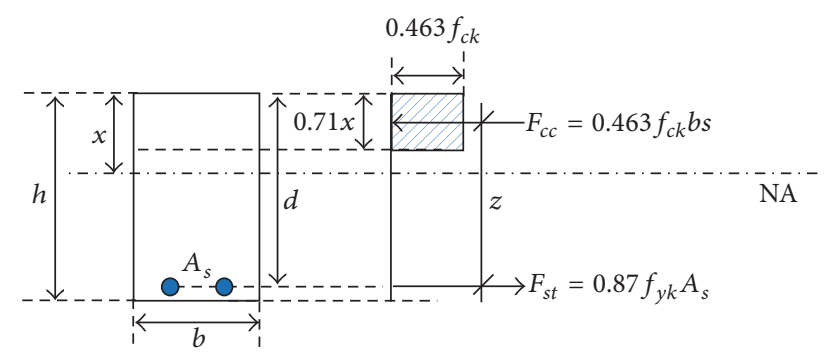

Figure 6: Equivalent stress block diagram for HSC, EC2 [16].

Although all beams have been designed to resist shear forces in accordance with the requirements of EC2, nevertheless, beams B7 and B8 have failed in shear. As shown in Table 6, the differences in ultimate moments between values predicted using EC2 guidelines and experimental values increase as the steel reinforcement ratio increases. This is due to the fact that EC2 models are neglecting tensile strength of SC-ECC and,

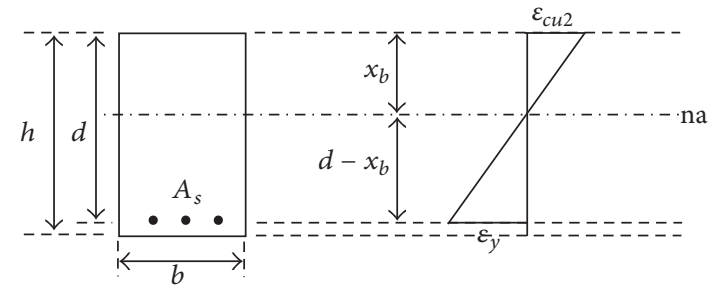

FIgURE 7: Strain diagram of R-ECC according to EC2.

therefore, are unable to predict the accurate tensile force in tension zone.

The shear span to effective depth ratio $\left(a_{v} / d\right)$ is 2.79 in this study. The failure mode of beams B7 and B8 is classified as shear failure mode and identified as a diagonal tension failure which is comparable to normal reinforced concrete failure [21]. The initial bending crack becomes inclined at early loading stage and propagates slowly to the loading point and then extends along the tension steel bar. The failure has occurred due to destruction of the bond between the tension steel and the concrete as shown in Figure 10. The tension reinforcement steel does not reach the yield values as indicated in Figure 11.

As long as the ECC in the compression zone has not reached the maximum compressive strain, the moment capacity of R-SC-ECC beam increases as steel reinforcement ratio increases. For beams B7 and B8 (with higher steel reinforcement ratio), flexural moment capacity had been 
TABLE 6: Ultimate moment ratio for R-SC-ECC.

\begin{tabular}{|c|c|c|c|c|c|c|c|c|}
\hline \multirow{4}{*}{ Beam number } & \multirow{4}{*}{ Steel reinf. ratio, $\rho$} & \multicolumn{4}{|c|}{ Ultimate moment, $M_{u}(\mathrm{kNm})$} & \multicolumn{3}{|c|}{ Ultimate moment ratio } \\
\hline & & \multirow{3}{*}{$\begin{array}{l}\operatorname{Exp} \\
M_{u}^{\mathrm{Ex}}\end{array}$} & \multicolumn{2}{|c|}{ Analysis } & \multirow{3}{*}{$\begin{array}{c}\text { FEM } \\
\text { VecTor2 } \\
M_{u}^{\text {Vec2 }}\end{array}$} & \multirow{3}{*}{$\begin{array}{l}\mathrm{EC} 2 / \operatorname{Exp} \\
M_{u}^{\mathrm{EC}} / M_{u}^{\mathrm{Ex}}\end{array}$} & \multirow{3}{*}{$\begin{array}{c}\mathrm{R} / \operatorname{Exp} \\
M_{u}^{\mathrm{R}} / M_{u}^{\mathrm{Ex}}\end{array}$} & \multirow{3}{*}{$\begin{array}{l}\text { Vec2/Exp } \\
M_{u}^{\mathrm{Vec} 2} / M_{u}^{\mathrm{Ex}}\end{array}$} \\
\hline & & & $\mathrm{EC} 2$ & RILEM & & & & \\
\hline & & & $M_{u}^{\mathrm{EC}}$ & $M_{u}^{\mathrm{R}}$ & & & & \\
\hline B1 & 0.558 & 33.42 & 22.56 & 50.41 & 45.12 & 0.67 & 1.51 & 1.35 \\
\hline B2 & 0.388 & 35.14 & 16.81 & 45.53 & 40.75 & 0.48 & 1.30 & 1.16 \\
\hline B3 & 0.993 & 80.78 & 42.48 & 67.5 & 81.2 & 0.53 & 0.84 & 1.01 \\
\hline B4 & 0.752 & 46.94 & 31.01 & 57.27 & 50.82 & 0.66 & 1.22 & 1.08 \\
\hline B5 & 1.272 & 91.35 & 51.48 & 76.42 & 93.53 & 0.56 & 0.84 & 1.02 \\
\hline B6 & 1.49 & 115.31 & 61.92 & 84.57 & 117.8 & 0.54 & 0.73 & 1.02 \\
\hline B7 & 1.986 & 113.17 & 77.42 & 98.49 & 128.23 & 0.68 & 0.87 & 1.13 \\
\hline \multirow[t]{4}{*}{ B8 } & 2.03 & 111.87 & 83.72 & 106.74 & 131.98 & 0.75 & 0.95 & 1.18 \\
\hline & \multicolumn{4}{|c|}{ Mean $(M)$} & & 0.61 & 1.03 & 1.12 \\
\hline & \multicolumn{4}{|c|}{ Standard deviation $(S)$} & & 0.09 & 0.26 & 0.11 \\
\hline & \multicolumn{4}{|c|}{ Coefficient of variation $(\mathrm{CoV})$} & & 0.15 & 0.25 & 0.09 \\
\hline
\end{tabular}

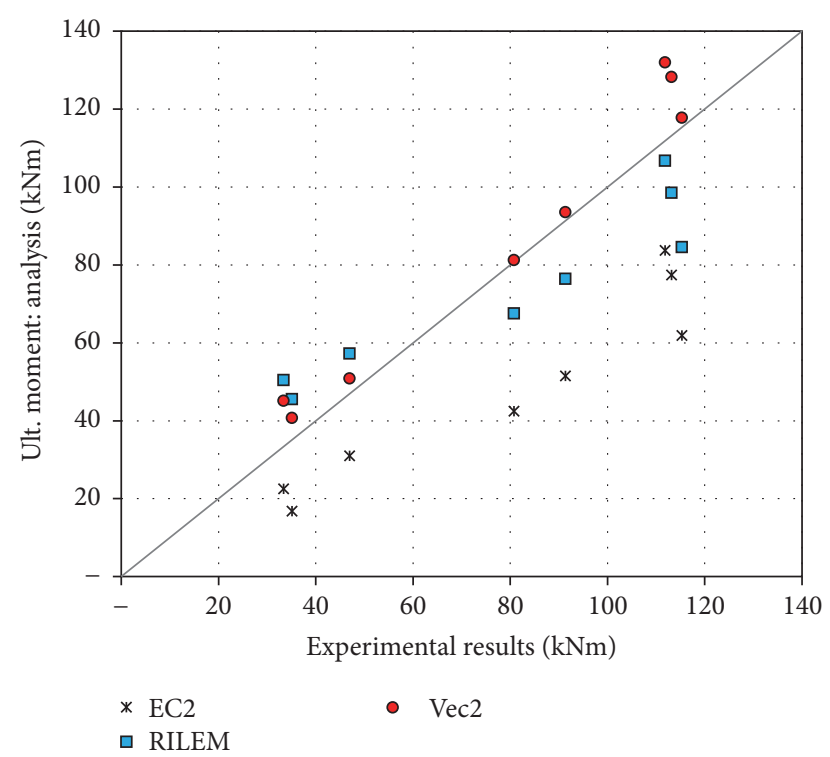

FIgURE 8: Distribution of ultimate moment ratio.

TABLE 7: Cracks width for R-SC-ECC beams at service load.

\begin{tabular}{lc}
\hline Beam number & $\begin{array}{c}\text { Flexural cracks width at service } \\
\text { load, mm }\end{array}$ \\
\hline B1 & 0.69 \\
B2 & 0.61 \\
B3 & 0.57 \\
B4 & 0.52 \\
B5 & 0.49 \\
B6 & 0.47 \\
\hline
\end{tabular}

increased which consequently led to an increase in shear stress. However, these beams failed in shear as the shear reinforcement was kept constant throughout the beams.

The stress flow and map cracks at failure of the R-SC-ECC beams have been developed using VecTor2 FEM analysis.
The stress flow and map cracks for beams B1-B6 and B7B8 are shown in Figures 12, 13 and 14, 15, respectively. The VecTor2 FEM analysis results are in good agreement with the experimental results. For beams B1 to B6, the stress flows and cracks occurred in constant-moment zone dominantly (Figures 12 and 13), while, for beams B7 and B8, the stress flows and cracks occurred in the shear zone as well and were more concentrated (Figures 14 and 15).

3.3. Ductility Class for R-SC-ECC. Ductility is the ability of structural component to undergo large deformations beyond yielding point without breaking [22]. In this study, ductility of R-SC-ECC beam is the area under the load-deflection curve of the beam measured by dividing the final deflection over deflection at yielding point. It is an important feature of reinforced concrete structures as the failure of the beam will be gradual and gives signs of failure. Eurocode8 has specified three ductility classes, $q$ : low class with behavior factor less than 1.5 , medium class with behavior factor between 1.5 and 4 , and high class with behavior factor greater than 4 . The ductility class, $q$, can be computed from

$$
q=\frac{F_{e l}}{F_{y}},
$$

where $F_{e l}$ is the maximum load and $F_{y}$ is the yield load. However, as the test is a static test, therefore the ductility class $q$ is equal to the ductility ratio $\mu$, whereas the ductility ratio is equal to the ratio of the deflection at final failure $D_{u}$ to deflection at yielding $D_{y}$. The load versus deflection curve for each R-SC-ECC beam is shown in Figure 16 and the ductility ratio for beams has been computed as shown in Table 8 . For beams B1 to B6, in which the beams failed in flexure mode, at lower steel reinforcement ratio (up to 0.558 ), beams exhibited middle ductility and fell in the range of ductility class medium with ductility ratio higher than 1.5. Nevertheless, the beams that have higher steel reinforcement ratio (larger than 0.752 and less than 1.986) showed ductility ratio greater than 4 , which classifies them as ductility class high. 


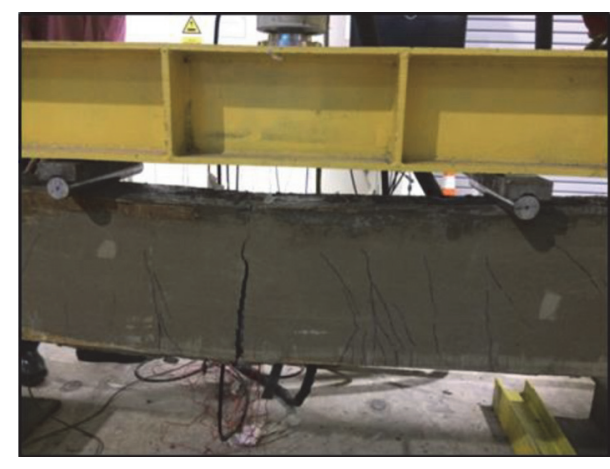

(a) Failure mode of beams B1-B6

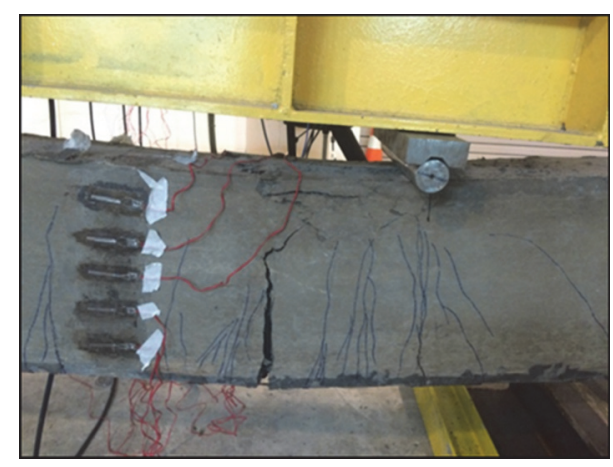

(b) Crack pattern of beams B1-B6

FIGURE 9: Typical flexural failure modes for beams B1 to B6.

TABLE 8: Ductility ratio for R-SC-ECC beams (experimental results).

\begin{tabular}{lccc}
\hline Beam & Deflection at yield, $D_{y}(\mathrm{~mm})$ & Deflection at failure, $D_{u}(\mathrm{~mm})$ & Ductility ratio, $D_{u} / D_{y}$ \\
\hline B1 & 8.76 & 18.41 & 2.1 \\
B2 & 5.2 & 17.84 & 3.43 \\
B3 & 7.16 & 32.08 & 4.48 \\
B4 & 6.13 & 26.45 & 4.31 \\
B5 & 8.95 & 41.41 & 4.62 \\
B6 & 8.25 & 40 & 4.84 \\
B7 & 10.04 & 18.33 & 1.83 \\
B8 & 7.45 & 16.84 & 2.26 \\
\hline
\end{tabular}

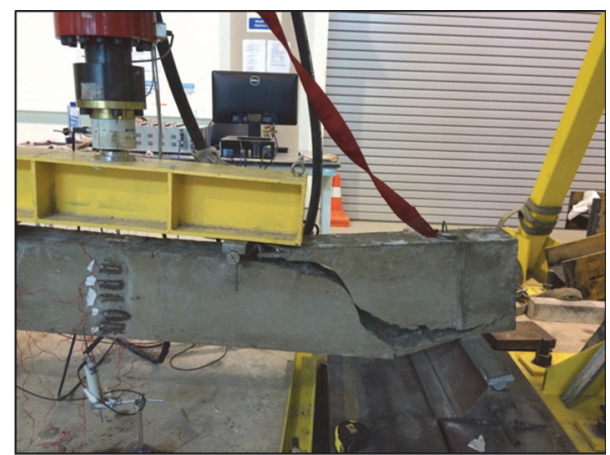

Figure 10: Typical shear failure mode of beams B7 and B8.

Eurocode8 suggests that, in regions with medium to high seismic activities, beams with ductility class medium to high can be used. This is necessary to ensure that the beams have the ability to absorb energy.

Although beams B7 and B8 failed in shear, nevertheless, these beams exhibited good ductility ratios, which are 1.83 and 2.26, respectively. It is worth noting that B7 and B8 are categorized as ductility class medium. This is due to ECC ductility superiority compared to normal concrete, in which tailoring of ECC (mechanical interactions between the fibers, matrix, and interface) can provide good performance even if the cracks' width is wider ( $\mathrm{Li}[23])$. In this study, it was found that the optimum ductility has been achieved by beam B6 with steel reinforcement ratio $(\rho)$ of 1.49 .

The behavior of ECC structural elements has been investigated and elaborated [6, 24-27]. In this study, superiority of ECC can be proved compared to normal concrete such as behavior of ECC in direct tensile test and compression stressstrain test as shown in Figures 17 and 18, respectively.

According to this investigation, ECC has high tensile strength of $4.87 \mathrm{MPa}$ (2.44-fold higher compared to normal strength concrete) and its strain capacity is larger by $545 \%$ compared to normal strength concrete (NSC). ECC exhibits strain hardening and its descending curve is quite smooth (softening) after postpeak condition, whereas compression stress-strain curve of ECC exhibits an ascending pattern at prepeak condition with smaller tangential angle compared to VecTor2 prepeak models due to lower elastic modulus of $22 \mathrm{GPa}$ for ECC. Based on ACI provision (2008), ECC was categorized as high strength concrete (HSC), in which ECC has compressive strength of $86.5 \mathrm{MPa}$. Unlike ECC, elastic modulus of HSC is usually greater than $24 \mathrm{GPa}$ and exhibits sudden and explosive crushing. Nevertheless, due to the strong bonding between fibers and cementitious matrix, the peak condition of ECC is always attained on slow pace and the ECC crushing is always marked by bulging behavior. The ECC behavior is specific and rather different compared to available VecTor2 prepeak models. Basically, the compression stress-strain curve of VecTor2 prepeak models is based on 


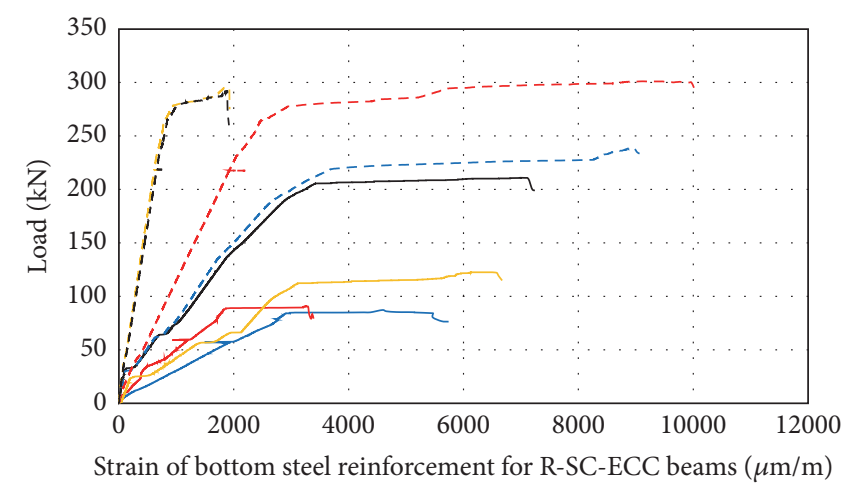

$\begin{aligned} \text { B1 } & --\mathrm{B} 5 \\ -\mathrm{B} 2 & ---\mathrm{B} 6 \\ -\mathrm{B} 3 & --\mathrm{B} 7 \\ \mathrm{~B} 4 & ---\mathrm{B} 8\end{aligned}$

(a) Load-strain relationship (for longitudinal steel reinforcement)

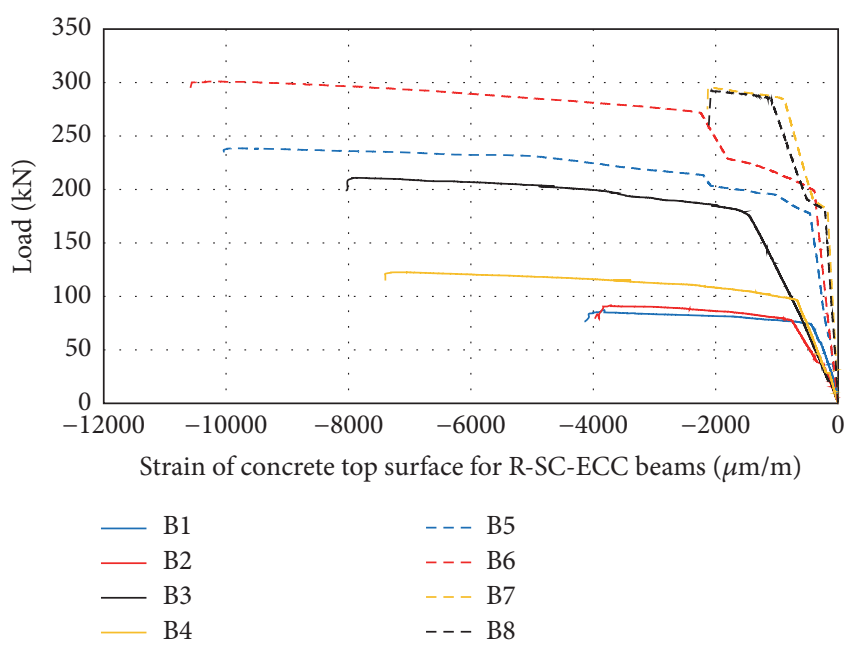

(b) Load-strain relationship (for concrete)

FIGURE 11: Strain of steel bars and concrete.

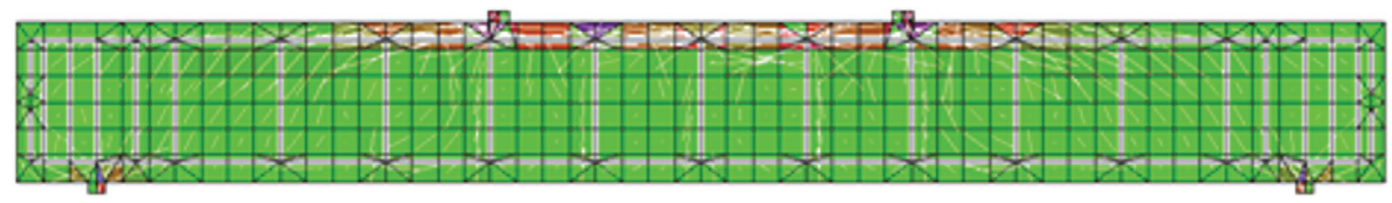

FIgURE 12: Typical stress flow at flexural failure modes of beams B1-B6 (VecTor2 analysis).

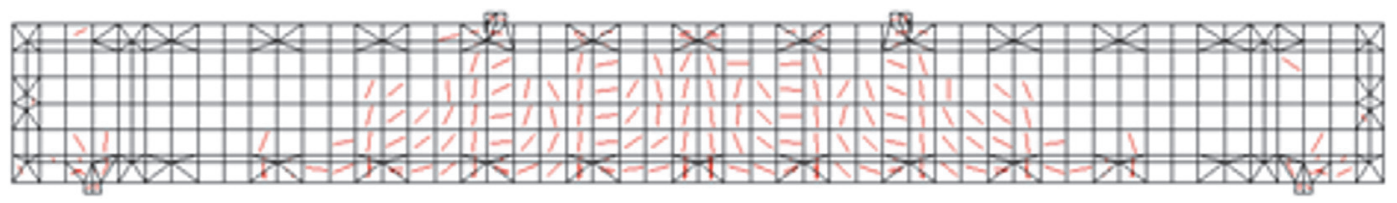

FIGURE 13: Typical map cracks in flexure region of beams B1-B6 (VecTor2 analysis).

elastic modulus of larger than $24 \mathrm{GPa}$, even though it utilizes Popovic-HSC models. In this study, all available prepeak models of VecTor2 have been investigated and ECC properties (experimental results) have been utilized to simulate the most appropriate model. Therefore, load-deformation curves of R-SC-ECC beams exhibit smaller tangential angle compared to curves obtained from VecTor 2 analysis as shown in Figures 20 and 21.

As indicated in the previous sections, RILEM and EC2 models are not suitable for predicting ultimate moments for R-SC-ECC beams. However, VecTor2 FEM analysis results showed good agreement in predicting the ultimate moments capacities and cracks patterns. To evaluate further the suitability of the VecTor2 FEM analysis, load versus deflection for all beams has been created as shown in Figure 19 and the predicted ultimate loads have been compared with the experimental values as shown in Table 9. The predicted ultimate loads using VecTor2 FEM analysis have shown good agreement with the experimental ultimate loads values.

Comparisons of experimental results with VecTor2 analysis at load-deflection relationships for R-SC-ECC beams are shown in Figures 20 and 21. For prepeak condition, it has been noticed that Popovic-high strength concrete (HSC) model yields larger tangential angle compared to experimental results. And after postpeak condition, the curve of VecTor2 model shows some fluctuations. Basically, to obtain appropriate models in VecTor2, ECC actual properties have been utilized. In addition, VecTor 2 models have been selected on trial-and-error basis, in which the following postpeak models have been considered: Popovic/Mander (as compression postpeak model), Vecchio 1992 (as compression softening model), Modified Bentz 2003 (as tension stiffening model), Nonlinear Yamamoto (as tension softening model), Selby (as confined strength model), Variable-Montoya with limit (as dilatation model), and Mohr-Coulomb Stress (as cracking criterion model).

The behavior of the postpeak models becomes comparable to the experimental results after the models reach the maximum stage up to final failure. The predicted ultimate loads and final deflections by VecTor 2 are in good agreement with the experimental results as shown in Table 9 and Figures 20 and 21. 


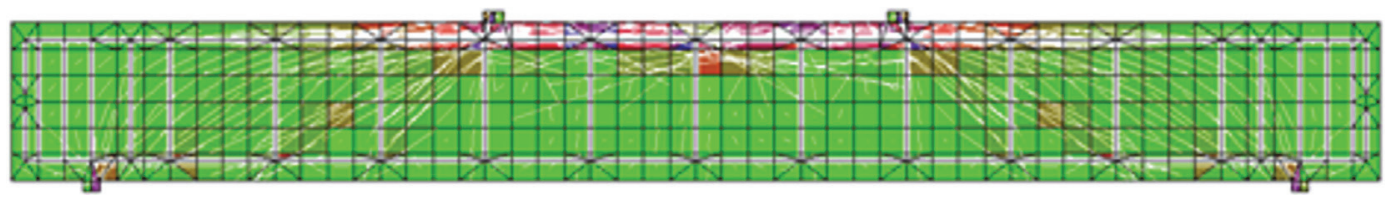

FIGURE 14: Typical stress flow at shear failure modes of beams B7-B8 (VecTor2 analysis).

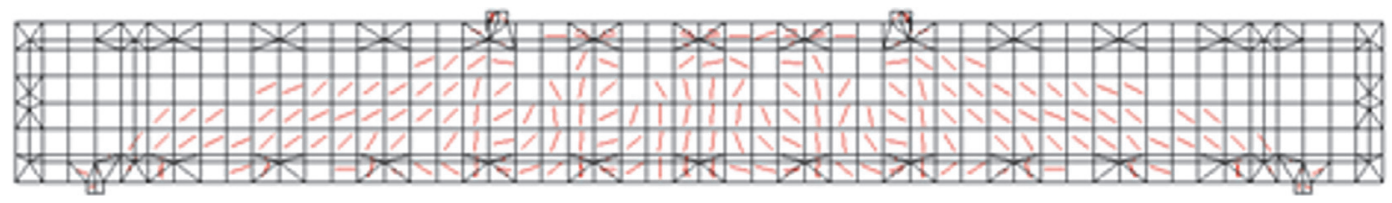

FIgURE 15: Typical map cracks in shear region of beams B7-B8 (VecTor2 analysis).

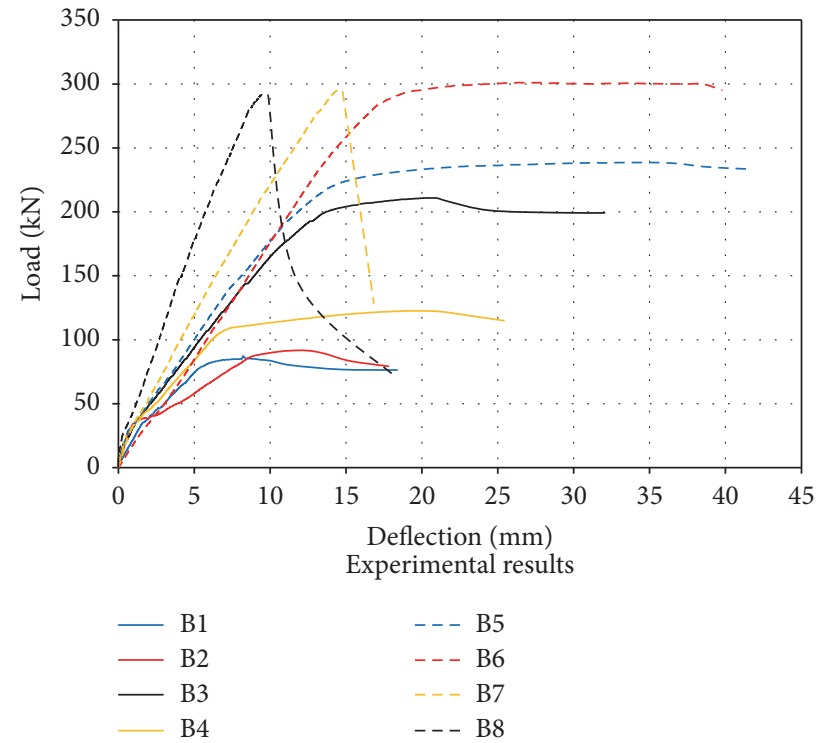

FIGURE 16: Load-deflection relationships for R-SC-ECC beams.

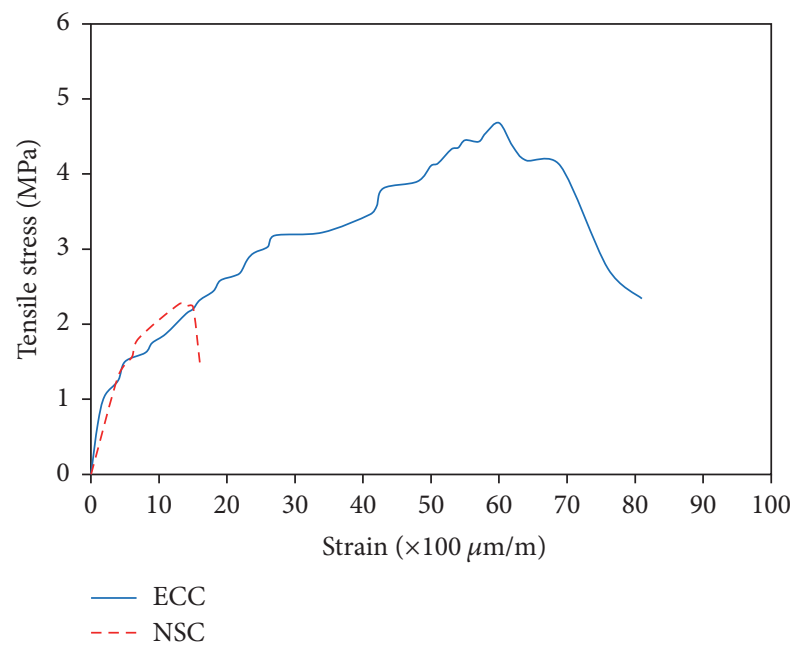

FIgURE 17: Direct tensile strength: ECC and NSC.

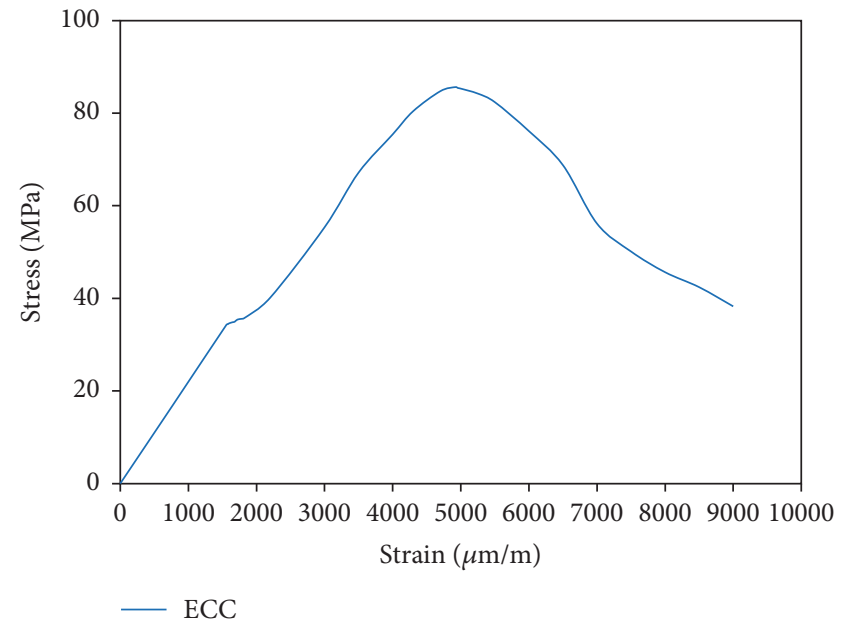

FIGURE 18: Compression stress-strain curve: ECC.

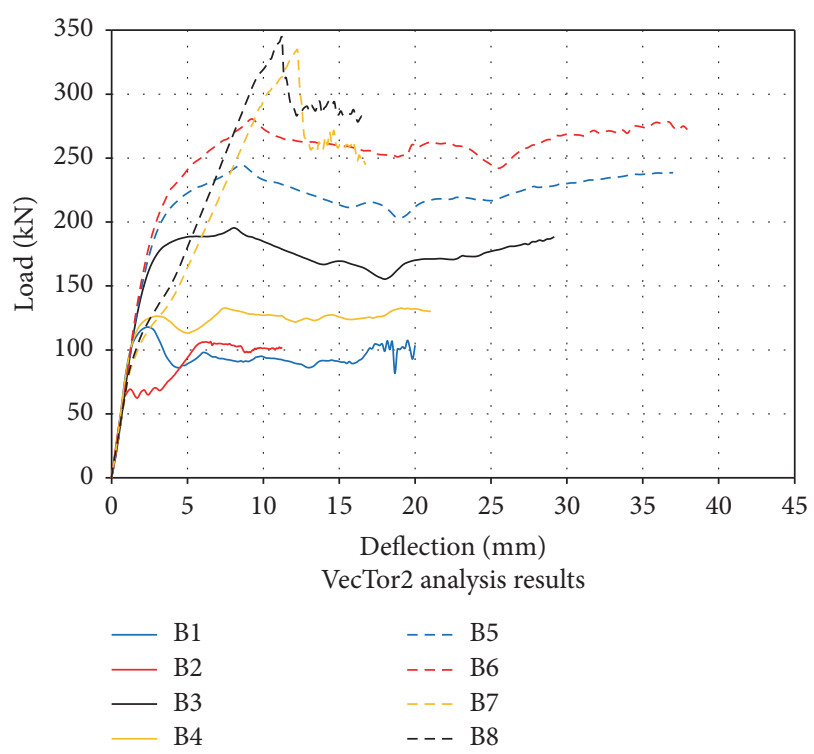

FIGURE 19: Load-deformation relationships for R-SC-ECC beams. 


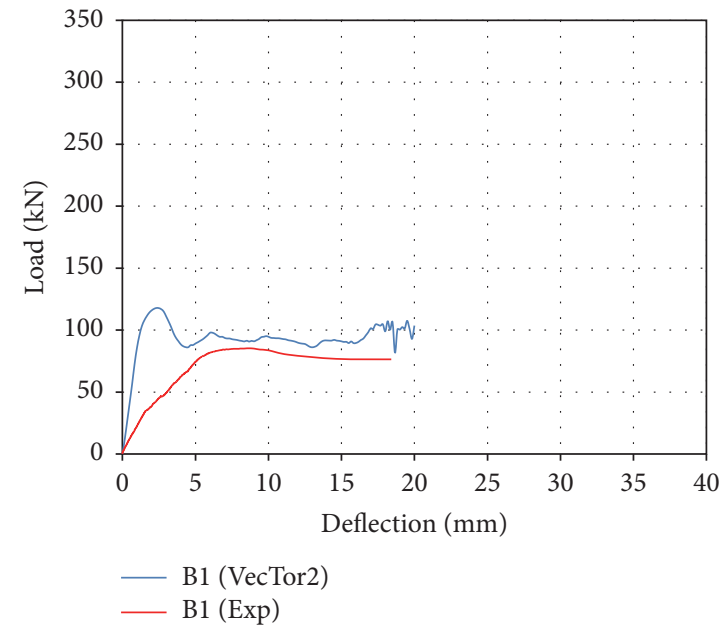

(a) Beam B1

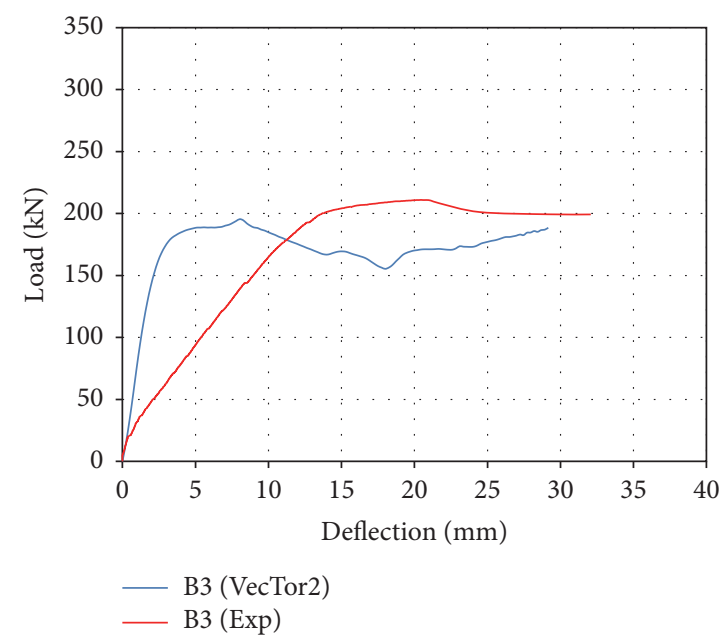

(c) Beam B3

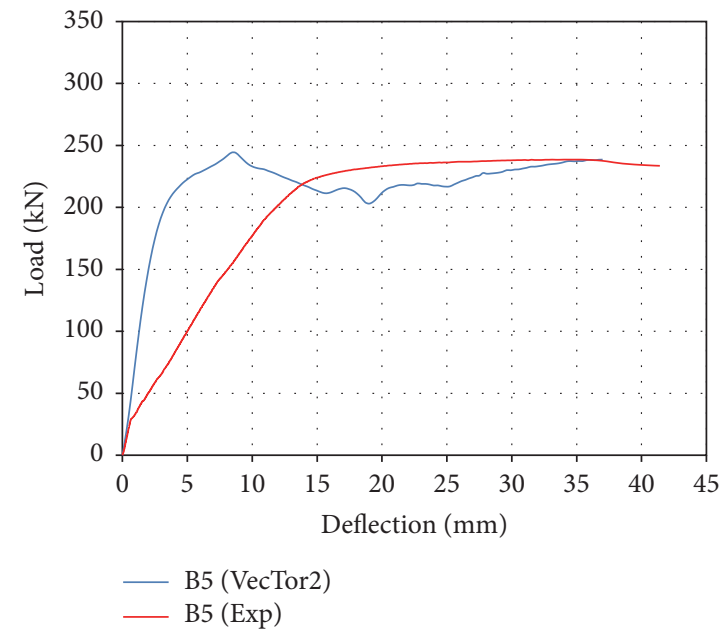

(e) Beam B5

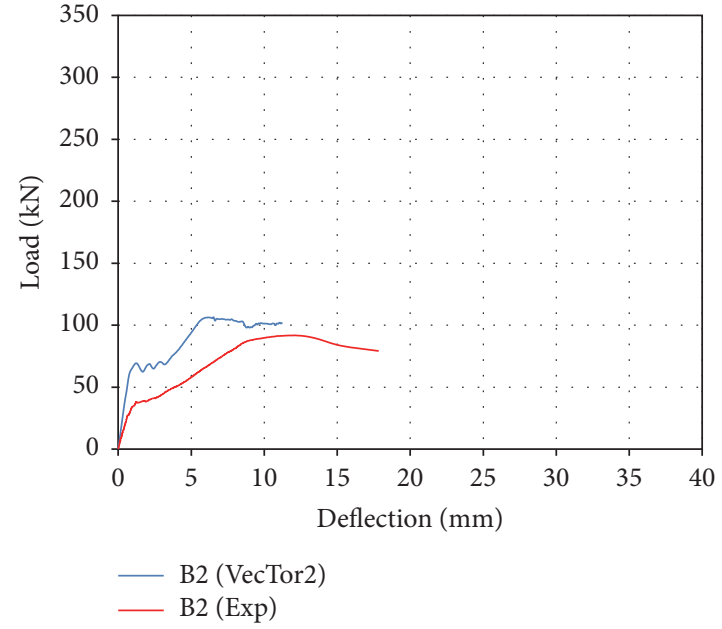

(b) Beam B2

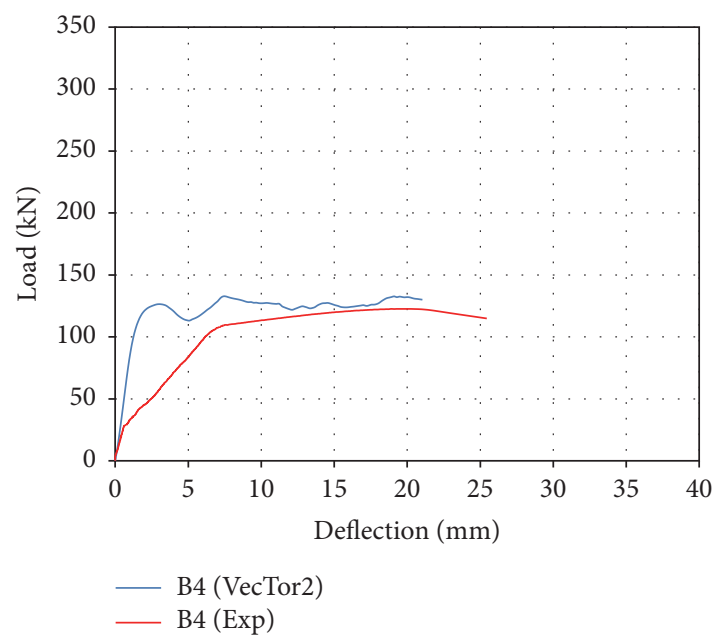

(d) Beam B4

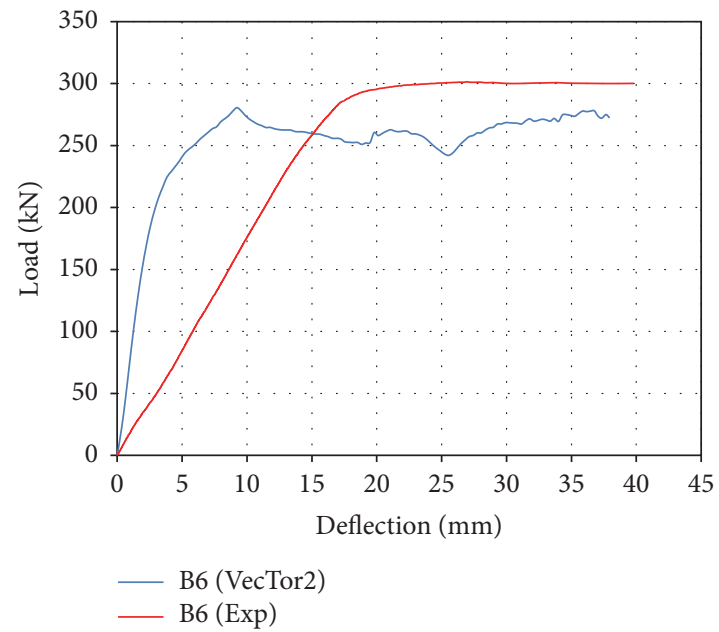

(f) Beam B6

FIGURE 20: Load-deflection relationships for R-SC-ECC beams. 


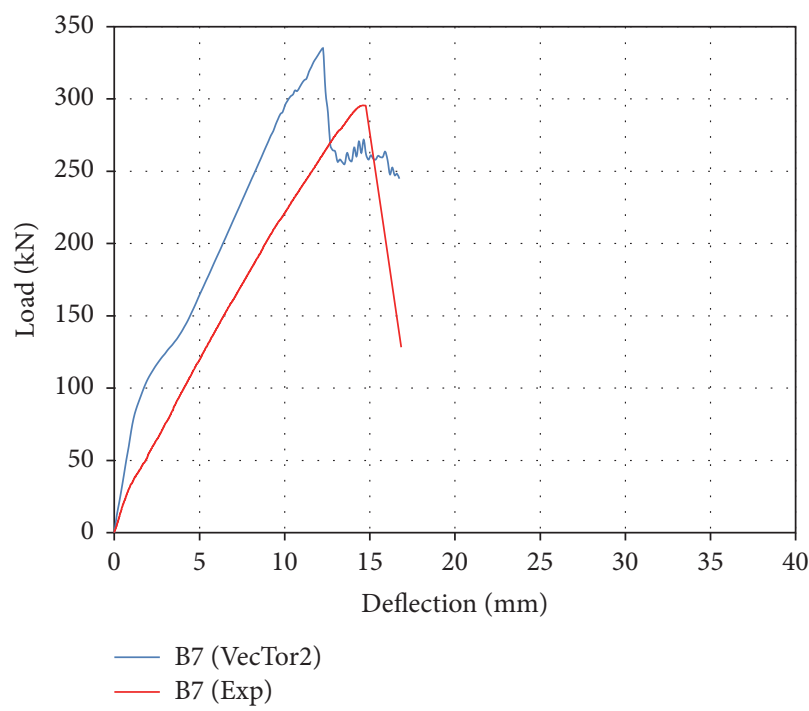

(a) Beam B7

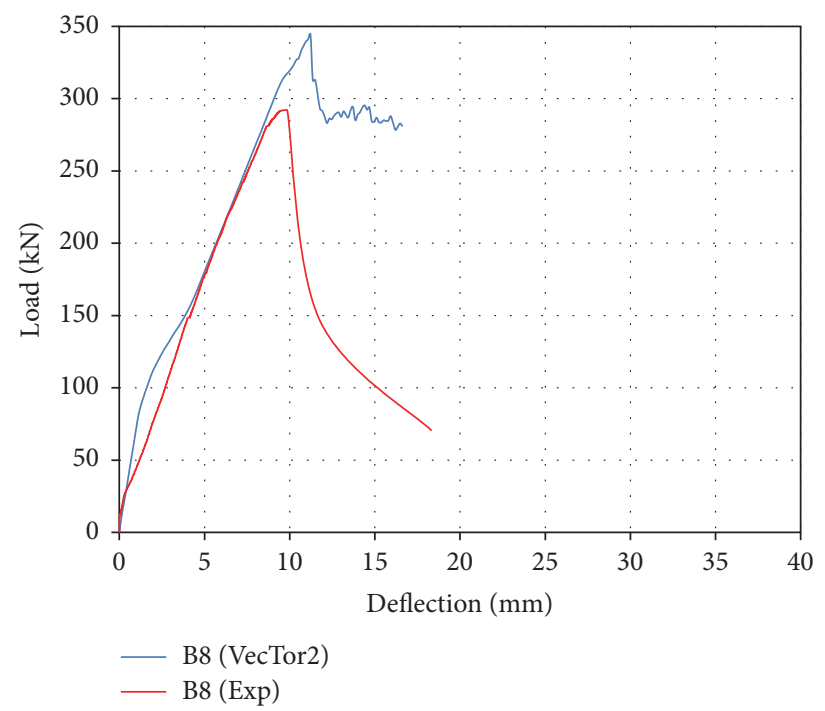

(b) Beam B8

FIGURE 21: Load-deflection relationships for R-SC-ECC beams.

TABLE 9: Ultimate load deflection: VecTor2 and experimental results.

\begin{tabular}{|c|c|c|c|c|c|c|c|}
\hline \multirow{2}{*}{ Beam number } & \multirow{2}{*}{ Steel reinf. ratio, $\rho$} & \multicolumn{2}{|c|}{ Load at ultimate stage $(\mathrm{kN})$} & \multicolumn{2}{|c|}{ Deflection at rupture $(\mathrm{mm})$} & \multicolumn{2}{|c|}{ Ratio } \\
\hline & & $\operatorname{Exp}\left(P_{\mathrm{Ex}}\right)$ & VecTor2 $\left(P_{\mathrm{Vec} 2}\right)$ & $\operatorname{Exp}\left(D_{\mathrm{Ex}}\right)$ & VecTor2 $\left(D_{\mathrm{Vec} 2}\right)$ & $\begin{array}{l}\mathrm{Vec} 2 / \mathrm{Exp} \\
\left(P_{\mathrm{Vec} 2} / P_{\mathrm{Ex}}\right)\end{array}$ & $\begin{array}{c}\mathrm{Vec} 2 / \mathrm{Exp} \\
\left(D_{\mathrm{Vec} 2} / D_{\mathrm{Ex}}\right)\end{array}$ \\
\hline B1 & 0.558 & 87.27 & 117.8 & 18.41 & 19.99 & 1.35 & 1.09 \\
\hline B2 & 0.388 & 91.76 & 106.4 & 17.84 & 11.24 & 1.16 & 0.63 \\
\hline B3 & 0.993 & 210.92 & 195.4 & 32.08 & 29.17 & 0.93 & 0.91 \\
\hline B4 & 0.752 & 122.55 & 132.7 & 26.45 & 21.04 & 1.08 & 0.80 \\
\hline B5 & 1.272 & 238.5 & 244.2 & 41.41 & 36.99 & 1.02 & 0.89 \\
\hline B6 & 1.49 & 301.08 & 280.5 & 40.00 & 37.94 & 0.93 & 0.95 \\
\hline B7 & 1.986 & 295.48 & 334.8 & 18.33 & 16.74 & 1.13 & 0.91 \\
\hline B8 & 2.03 & 292.08 & 344.6 & 16.84 & 16.60 & 1.18 & 0.91 \\
\hline \multicolumn{6}{|c|}{ Mean } & 1.10 & 0.90 \\
\hline
\end{tabular}

Therefore, to obtain reasonable structural behavior of RSC-ECC, VecTor2 is an appropriate package as it contains concrete models, reinforcement models, and bond models. The concrete models include compression prepeak and postpeak response, compression softening, tension stiffening and softening, tension splitting, confined strength, and crack, whereas reinforcement models include hysteretic response, dowel action, and buckling.

\section{Conclusions}

The following conclusions can be drawn from this study:

(1) The flexural and shear failure modes for R-SC-ECC beams are comparable to failure modes of normal reinforced concrete beams.

(2) Predicting the ultimate moments of R-SC-ECC beams using EC2 models yields very conservative results due to neglecting tensile strength of SC-ECC in the computing of ultimate strengths.

(3) RILEM models are suitable for predicting ultimate strength of R-SC-ECC beams with small reinforcement ratios. However, as reinforcement ratio increases, RILEM models will yield results that are more conservative.

(4) Finite element models using VecTor2 package have successfully predicted the structural behavior of RSC-ECC beams including failure modes, ultimate moments, failure loads, and deflections.

(5) R-SC-ECC beams exhibit ductility class medium to high. Therefore, ECC is very suitable for regions with seismic activities as ECC has the ability to absorb energy. 


\section{Competing Interests}

The authors declare that they have no competing interests.

\section{References}

[1] S. H. Said and H. Abdul Razak, "Structural behavior of RC engineered cementitious composite (ECC) exterior beam-column joints under reversed cyclic loading," Construction and Building Materials, vol. 107, pp. 226-234, 2016.

[2] S. H. Said and H. A. Razak, "The effect of synthetic polyethylene fiber on the strain hardening behavior of engineered cementitious composite (ECC)," Materials and Design, vol. 86, pp. 447457, 2015.

[3] C.-C. Hung, W.-M. Yen, and K.-H. Yu, "Vulnerability and improvement of reinforced ECC flexural members under displacement reversals: experimental investigation and computational analysis," Construction and Building Materials, vol. 107, pp. 287-298, 2016.

[4] S. H. Said, H. A. Razak, and I. Othman, "Flexural behavior of engineered cementitious composite (ECC) slabs with polyvinyl alcohol fibers," Construction and Building Materials, vol. 75, pp. 176-188, 2015.

[5] Q. Zhang and V. C. Li, "Development of durable sprayapplied fire-resistive Engineered Cementitious Composites (SFR-ECC)," Cement and Concrete Composites, vol. 60, pp. 1016, 2015.

[6] B. S. Mohammed, M. Aswin, W. H. Beatty, and M. Hafiz, "Longitudinal shear resistance of PVA-ECC composite slabs," Structures, vol. 5, pp. 247-257, 2016.

[7] C.-C. Hung and Y.-S. Chen, "Innovative ECC jacketing for retrofitting shear-deficient RC members," Construction and Building Materials, vol. 111, pp. 408-418, 2016.

[8] Z. Pan, C. Wu, J. Liu, W. Wang, and J. Liu, "Study on mechanical properties of cost-effective polyvinyl alcohol engineered cementitious composites (PVA-ECC)," Construction and Building Materials, vol. 78, pp. 397-404, 2015.

[9] Z. Zhang, S. Qian, and H. Ma, "Investigating mechanical properties and self-healing behavior of micro-cracked ECC with different volume of fly ash," Construction and Building Materials, vol. 52, pp. 17-23, 2014.

[10] J. Yu, J. Lin, Z. Zhang, and V. C. Li, "Mechanical performance of ECC with high-volume fly ash after sub-elevated temperatures," Construction and Building Materials, vol. 99, pp. 82-89, 2015.

[11] A. R. Sakulich and V. C. Li, "Nanoscale characterization of engineered cementitious composites (ECC)," Cement and Concrete Research, vol. 41, no. 2, pp. 169-175, 2011.

[12] K. Amini, I. Mehdipour, S. D. Hwang, and M. Shekarchi, "Effect of binder composition on time-dependent stability and robustness characteristics of self-consolidating mortar subjected to prolonged agitation," Construction and Building Materials, vol. 112, pp. 654-665, 2016.

[13] L. Señas, C. Priano, and S. Marfil, "Influence of recycled aggregates on properties of self-consolidating concretes," Construction and Building Materials, vol. 113, pp. 498-505, 2016.

[14] M. M. Kamal, M. A. Safan, Z. A. Etman, and B. M. Kasem, "Mechanical properties of self-compacted fiber concrete mixes," HBRC Journal, vol. 10, no. 1, pp. 25-34, 2014.

[15] L. Vandewalle, "Recommendations of RILEM TC 162-TDF: Test and design methods for steel fibre reinforced concrete," Materials and Structures/Materiaux et Constructions, vol. 33, no. 225, pp. 3-5, 2000.
[16] Eurocode2, Design of concrete structures, Part 1-1: General rules and rules for buildings, 2004.

[17] F. J. Vecchio and P. S. Wong, VecTor2 \& Formworks User's Manual, University of Toronto, Toronto, Canada, 2002.

[18] F. J. Vecchio and M. P. Collins, "The modified compression field theory for reinforced concrete elements subject to shear," $A C I$ Journal, vol. 83, no. 2, pp. 219-231, 1986.

[19] F. J. Vecchio, "Disturbed stress field model for reinforced concrete: formulation," ASCE Journal of Structural Engineering, vol. 126, no. 9, pp. 1070-1077, 2000.

[20] B. S. Mohammed, W. L. Foo, and M. Abdullahi, "Flexural strength of palm oil clinker concrete beams," Materials and Design, vol. 53, pp. 325-331, 2014.

[21] B. S. Mohammed, W. L. Foo, K. M. A. Hossain, and M. Abdullahi, "Shear strength of palm oil clinker concrete beams," Materials and Design, vol. 46, pp. 270-276, 2013.

[22] Eurocode8, Design of Structures for Earthquake Resistance, Part 1: General Rules, Seismic Actions and Rules for Buildings, 2004.

[23] V. C. Li, "Hygral behavior of Engineered Cementitious Composite (ECC)," International Journal for Restoration of Buildings and Monuments, vol. 9, pp. 513-534, 2003.

[24] M. Aswin, B. S. Mohammed, M. S. Liew, and Z. I. Syed, "Shear failure of RC dapped-end beams," Advances in Materials Science and Engineering, vol. 2015, Article ID 309135, 11 pages, 2015.

[25] H. M. E.-D. Afefy and M. H. Mahmoud, "Structural performance of RC slabs provided by pre-cast ECC strips in tension cover zone," Construction and Building Materials, vol. 65, pp. 103-113, 2014.

[26] M. Maalej, S. T. Quek, S. F. U. Ahmed, J. Zhang, V. W. J. Lin, and K. S. Leong, "Review of potential structural applications of hybrid fiber Engineered Cementitious Composites," Construction and Building Materials, vol. 36, pp. 216-227, 2012.

[27] S. Qudah and M. Maalej, "Application of Engineered Cementitious Composites (ECC) in interior beam-column connections for enhanced seismic resistance," Engineering Structures, vol. 69, pp. 235-245, 2014. 

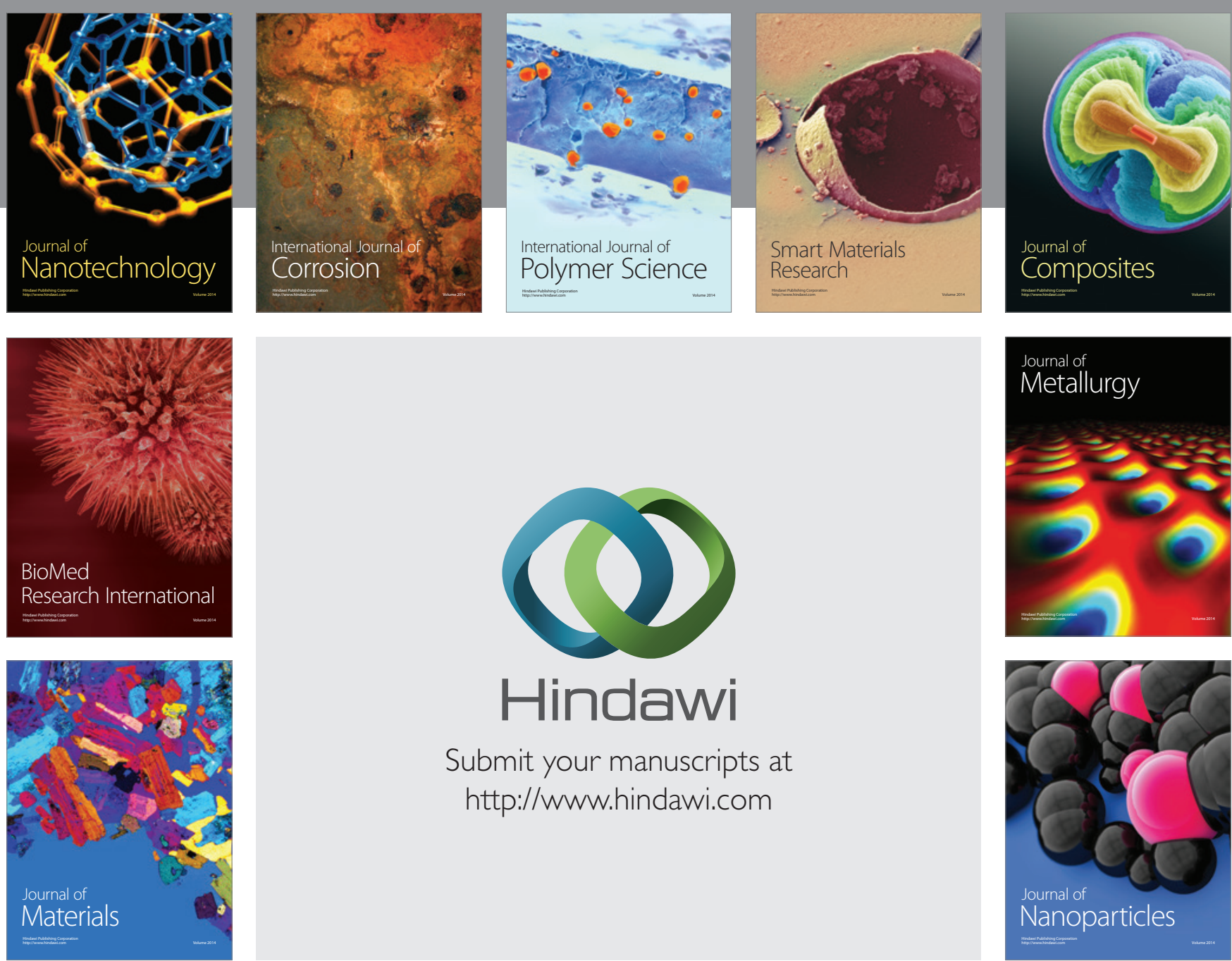

\section{Hindawi}

Submit your manuscripts at

http://www.hindawi.com

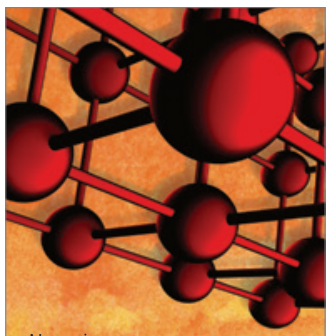

Materials Science and Engineering
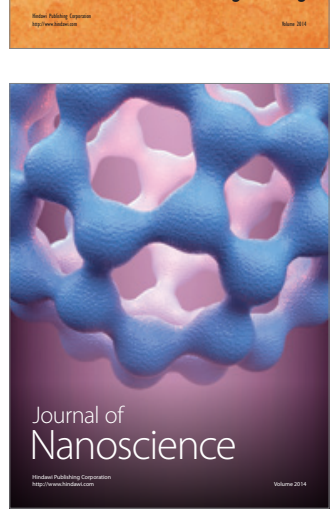
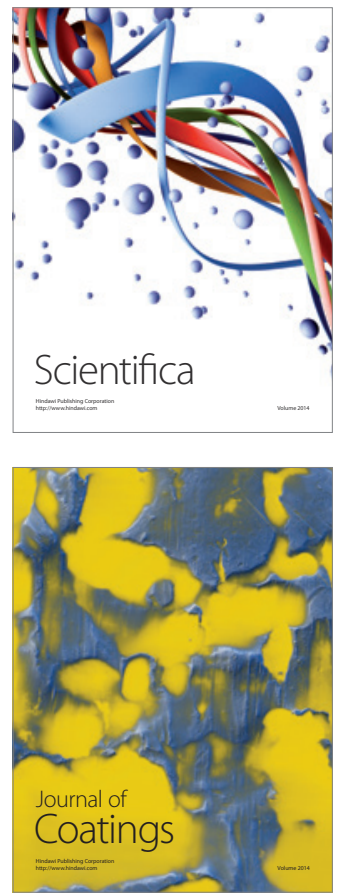
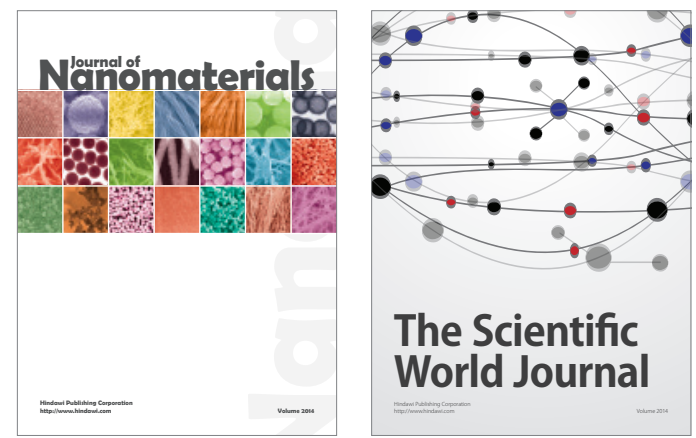

The Scientific World Journal
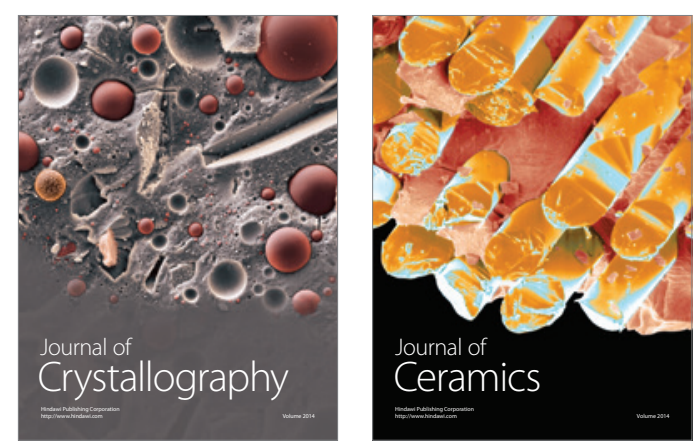
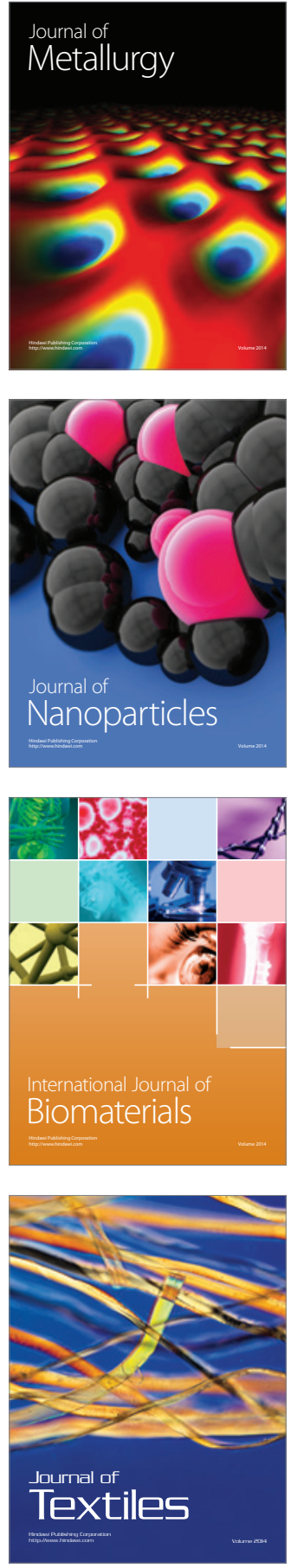